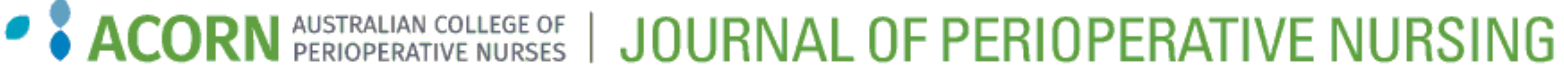

Volume 29 | Issue 1

Article 3

3-1-2016

\title{
The collaborative development of a pre-operative checklist: An e- Delphi study
}

Follow this and additional works at: https://www.journal.acorn.org.au/jpn

Part of the Health Services Administration Commons, Health Services Research Commons, Perioperative, Operating Room and Surgical Nursing Commons, and the Surgery Commons

(c) (†)

This work is licensed under a Creative Commons Attribution 4.0 License.

\section{Recommended Citation}

Murphy, Katherine; Walker, Kim; Duff, Jed; and Williams, Robyn (2016) "The collaborative development of a pre-operative checklist: An e-Delphi study," Journal of Perioperative Nursing: Vol. 29 : Iss. 1 , Article 3.

Available at: https://doi.org/10.26550/2209-1092.1002

https://www.journal.acorn.org.au/jpn/vol29/iss1/3

This Article is brought to you for free and open access by Journal of Perioperative Nursing. It has been accepted for inclusion in Journal of Perioperative Nursing by an authorized editor of Journal of Perioperative Nursing. 


\section{Authors}

Katherine Murphy

BN (Hons)

St Vincent's Private Hospital,

Darlinghurst, NSW

Kim Walker

BN, PhD

University of Tasmania, Sydney, NSW

Jed Duff

BN, PhD

St Vincent's Private Hospital,

Darlinghurst, NSW

\section{Robyn Williams}

BN, Grad Cert (Cardiac), BN (Edn)

St Vincent's Private Hospital,

Darlinghurst, NSW

\section{Corresponding author}

Katherine Murphy

St Vincent's Private Hospital,

Darlinghurst, NSW

katherine.murphy@svha.org.au

\section{The collaborative development of a pre-operative checklist: An e-Delphi study}

\author{
Abstract \\ The aim of this study was to identify which items should be \\ included in a pre-operative checklist based on recommendations \\ by nurse experts in order to promote patient safety and effective \\ communication in the perioperative environment.
}

Method: Thirty-five nurses participated in this e-Delphi study, which was conducted online via SurveyMonkey ${ }^{\circledR}$. Each survey presented participants with a list of potential items for inclusion in a pre-operative checklist. Participants were asked to identify items they felt should be included in the checklist with the option to include comments. Comments were de-identified and shared with other participants to allow confidential interaction. The surveys were analysed for consensus, determined as agreement between at least $70 \%$ of participants.

Results: Three survey rounds were completed. Forty-six items achieved consensus for inclusion in a pre-operative checklist.

Conclusion: The 46 items which achieved consensus were condensed to a list of 25 items categorised as: 1. Patient and procedure verification; 2. Preparation; and 3. Assessments. The findings of this study provide an evidence base for development of pre-operative checklists, to promote patient safety and effective communication in the perioperative environment.

\section{Keywords}

Perioperative, nursing, patient safety, communication, checklist.

\section{Background}

In health care worldwide, patient safety is of significant concern². Adverse events in the perioperative environment are commonly caused by non-technical skill failures such as teamwork and communication ${ }^{3}$.

In recent years, many hospitals have started using comprehensive checklist procedures ${ }^{4}$, which have demonstrated improvements in teamwork and patient safety in the perioperative environment ${ }^{5}$. The World Health Organization (WHO) Surgical Safety Checklist $^{6}$ is now well entrenched in most operating theatres. A great deal of literature has been published that discusses the benefits and improvements in patient safety since the checklist was implemented ${ }^{3,7-9}$. There is, however, a very limited evidence base to determine what safety checks should be performed prior to the patient entering the operating room. A literature search yielded little evidence to inform what items should be included in a pre-operative was to determine which items should be included in a pre-operative checklist, in order to promote patient safety, effective teamwork and better communication. checklist ${ }^{10-13}$. The aim of this study 


\section{Method}

\section{Design}

The e-Delphi method was chosen for this study. The Delphi method is a multi-iteration survey technique using expert opinion to achieve consensus on a specific issue ${ }^{14}$. The preceding ' $e$ ' indicates that the study was conducted online ${ }^{15}$.

\section{Recruitment}

An email was sent to all ACORN members, on behalf of the researchers, inviting eligible nurses to participate. Many recipients of this email also shared the information with colleagues, therefore having a snowball effect.

In order for participants to be considered experts, they each had a minimum of five years' experience in perioperative nursing and were selfassessed as having insight into the purpose and content of pre-operative checklists.

\section{Procedure}

The study was conducted online via SurveyMonkey ${ }^{\circledR 16}$. Participants remained anonymous to each other. The initial questionnaire consisted of potential checklist items. Potential checklist items were gathered from database and internet searches as well as example items submitted by participants. Participants selected either include or exclude for each item. Participants were encouraged to include reasons for their choice. Each subsequent survey round comprised checklist items which had not yet achieved consensus. Participants received feedback with each new survey, showing levels of consensus achieved so far and de-identified comments from other participants.

Checklist items were presented to participants, organised into five categories. The five categories were determined by the researchers:

1. Identification/procedural

2. Patient preparation

3. Diagnostics/pathology

4. Assessment

5. Present condition and patient history

Once an item achieved consensus for inclusion or exclusion, it was removed from future questionnaires.

Rates of participant consensus

\begin{tabular}{|c|c|c|c|c|c|c|}
\hline & \multicolumn{2}{|c|}{$\begin{array}{c}\text { Round } 1 \\
(n=35)\end{array}$} & \multicolumn{2}{|c|}{$\begin{array}{c}\text { Round } 2 \\
(n=34)\end{array}$} & \multicolumn{2}{|c|}{$\begin{array}{c}\text { Round } 3 \\
(n=33)\end{array}$} \\
\hline & $\begin{array}{l}\text { Include } \\
(\%)\end{array}$ & $\begin{array}{l}\text { Exclude } \\
(\%)\end{array}$ & $\begin{array}{l}\text { Include } \\
(\%)\end{array}$ & $\begin{array}{l}\text { Exclude } \\
(\%)\end{array}$ & $\begin{array}{l}\text { Include } \\
(\%)\end{array}$ & $\begin{array}{c}\text { Exclude } \\
(\%)\end{array}$ \\
\hline $\begin{array}{l}\text { Is the patient able to participate verbally in the verification/checklist process } \\
\text { independently? }\end{array}$ & 74 & 26 & - & - & - & - \\
\hline Confirm consent form is valid & 97 & 3 & - & - & - & - \\
\hline Specify any foreseeable communication issues & 89 & 11 & - & - & - & - \\
\hline Is an interpreter required? & 63 & 37 & 56 & 44 & 36 & 64 \\
\hline Patient states full name and date of birth. Confirmed against all documentation & 94 & 6 & - & - & - & - \\
\hline Patient confirms procedure to be performed including site and side & 89 & 11 & - & - & - & - \\
\hline Procedure including site and side (where applicable) stated by patient & 89 & 11 & - & - & - & - \\
\hline Patient confirms proceduralist/surgeon & 51 & 49 & 26 & 74 & - & - \\
\hline Has patient consented to blood transfusion, if required? & 75 & 25 & - & - & - & - \\
\hline Specify all known allergies and reaction(s) & 100 & 0 & - & - & - & - \\
\hline Patient ID bands including allergy/alert bands applied & 94 & 6 & - & - & - & - \\
\hline Sufficient number of patient identification labels available & 63 & 37 & 44 & 56 & 45 & 55 \\
\hline Specify anyone present at handover (e.g carer) & 51 & 49 & 65 & 35 & 67 & 33 \\
\hline $\begin{array}{l}\text { Contact details confirmed of person to notify on completion of surgery or in } \\
\text { emergency }\end{array}$ & 54 & 46 & 53 & 47 & 42 & 58 \\
\hline Does the patient require a medical certificate? & 37 & 63 & 29 & 71 & - & - \\
\hline Confirm that handover was taken from ward/admitting nurse & 80 & 20 & - & - & - & - \\
\hline Post-operative destination? & 34 & 66 & 15 & 85 & - & - \\
\hline Signatures of at least two nurses who have/are completing this checklist & 97 & 3 & - & - & - & - \\
\hline Person completing checklist to note any concerns in regards to this patient & 91 & 9 & - & - & - & - \\
\hline
\end{tabular}

Table 1.1: Identification/procedural items 
Rates of participant consensus

\begin{tabular}{|c|c|c|c|c|c|}
\hline \multicolumn{2}{|c|}{$\begin{array}{c}\text { Round } 1 \\
(n=35)\end{array}$} & \multicolumn{2}{|c|}{$\begin{array}{c}\text { Round } 2 \\
(n=34)\end{array}$} & \multicolumn{2}{|c|}{$\begin{array}{c}\text { Round } 3 \\
(n=33)\end{array}$} \\
\hline $\begin{array}{l}\text { Include } \\
(\%)\end{array}$ & $\begin{array}{c}\text { Exclude } \\
(\%)\end{array}$ & $\begin{array}{l}\text { Include } \\
(\%)\end{array}$ & $\begin{array}{c}\text { Exclude } \\
(\%)\end{array}$ & $\begin{array}{l}\text { Include } \\
(\%)\end{array}$ & $\begin{array}{c}\text { Exclude } \\
(\%)\end{array}$ \\
\hline 69 & 31 & 71 & 29 & - & - \\
\hline 40 & 60 & 24 & 76 & - & - \\
\hline 83 & 17 & - & - & - & - \\
\hline 86 & 14 & - & - & - & - \\
\hline 80 & 20 & - & - & - & - \\
\hline 71 & 29 & - & - & - & - \\
\hline 89 & 11 & - & - & - & - \\
\hline 77 & 23 & - & - & - & - \\
\hline 71 & 29 & - & - & - & - \\
\hline 66 & 34 & 65 & 35 & 76 & 24 \\
\hline 77 & 23 & - & - & - & - \\
\hline 97 & 3 & - & - & - & - \\
\hline 69 & 31 & 74 & 26 & - & - \\
\hline 57 & 43 & 38 & 62 & 39 & 61 \\
\hline 63 & 37 & 53 & 47 & 55 & 45 \\
\hline 54 & 46 & 56 & 44 & 64 & 36 \\
\hline 80 & 20 & - & - & - & - \\
\hline 100 & 0 & - & - & - & - \\
\hline 97 & 3 & - & - & - & - \\
\hline 74 & 26 & - & - & - & - \\
\hline
\end{tabular}

Person completing checklist to ask patient if they have any questions or concerns

Has the patient attended the pre-admission clinic?

Pre-medication charted

Pre-medication administered

Surgical site/side marked?

Surgical site preparation attended?

Procedure including site and side (where applicable) stated by patient

Is the patient currently taking blood thinning medications?

Has patient ceased any regular medication(s)? Include details

Is the patient currently receiving/ceased in last week cytotoxic medications?

DVT/VTE prophylaxis administered/in situ

Jewellery removed/taped

Hair pins or other accessories removed

Make-up removed

Nail polish removed

Patient in theatre attire

Specify date and time patient last passed urine or specify if catheterised

Date and time of last oral intake - fluids

Date and time of last oral intake - solids

Confirm list of all current medications including prescription, over the counter, etc.

Table 1.2: Patient preparation items

Rates of participant consensus

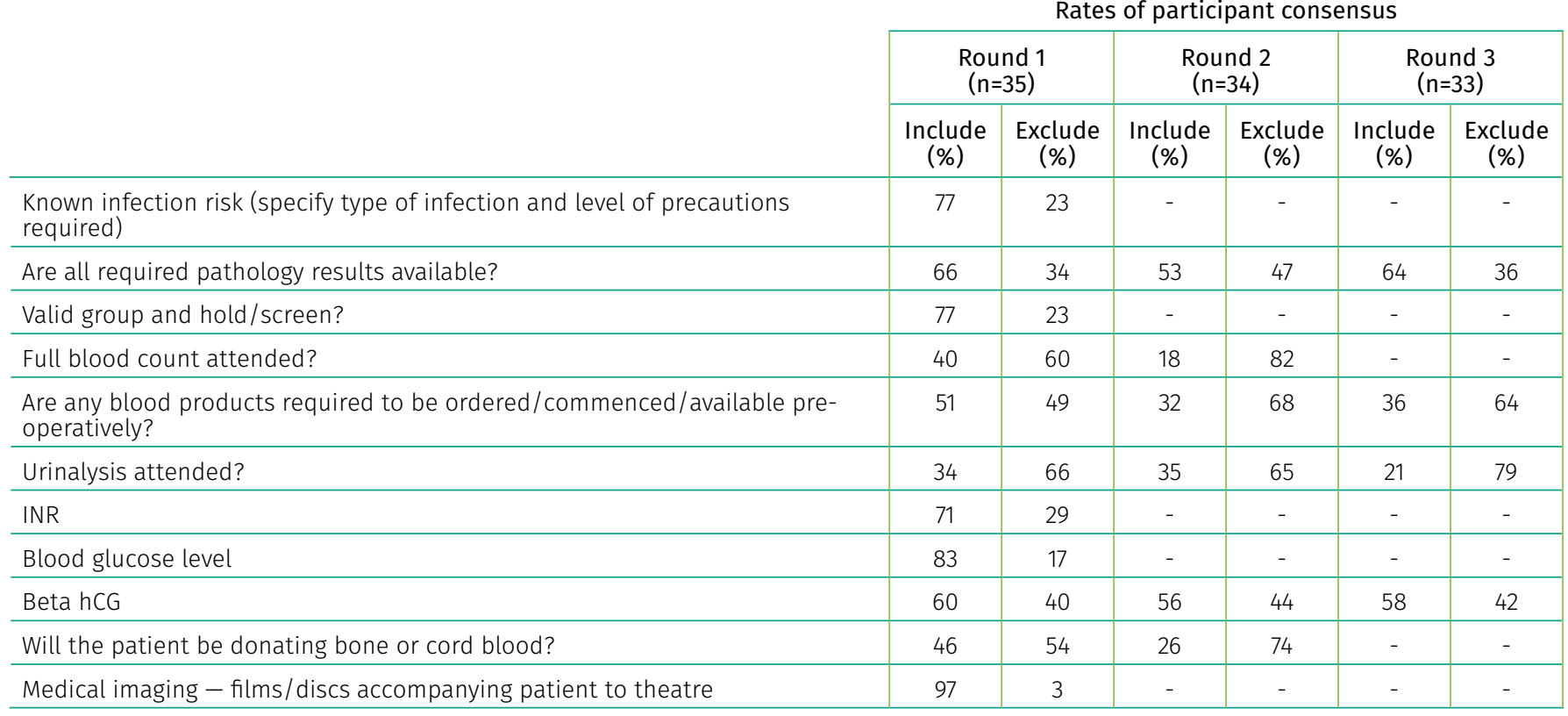

Table 1.3: Diagnostic/pathology items 
Rates of participant consensus

\begin{tabular}{|c|c|c|c|c|c|c|}
\hline & \multirow{2}{*}{\multicolumn{2}{|c|}{$\begin{array}{c}\text { Round } 1 \\
(n=35)\end{array}$}} & & & & \\
\hline & & & \multicolumn{2}{|c|}{$\begin{array}{c}\text { Round } 2 \\
(n=34)\end{array}$} & \multicolumn{2}{|c|}{$\begin{array}{c}\text { Round } 3 \\
(n=33)\end{array}$} \\
\hline & $\begin{array}{l}\text { Include } \\
(\%)\end{array}$ & $\begin{array}{l}\text { Exclude } \\
(\%)\end{array}$ & $\begin{array}{l}\text { Include } \\
(\%)\end{array}$ & $\begin{array}{l}\text { Exclude } \\
(\%)\end{array}$ & $\begin{array}{l}\text { Include } \\
(\%)\end{array}$ & $\begin{array}{l}\text { Exclude } \\
(\%)\end{array}$ \\
\hline Falls risk assessment completed & 51 & 49 & 44 & 56 & 36 & 64 \\
\hline Pressure area risk assessment completed & 66 & 34 & 71 & 29 & - & - \\
\hline DVT/VTE risk assessment completed & 66 & 34 & 44 & 56 & 58 & 42 \\
\hline Risk/history of obstructive sleep apnoea & 57 & 43 & 29 & 71 & - & - \\
\hline Skin integrity assessed & 77 & 23 & - & - & - & - \\
\hline Does the patient have any limitations with mobility? & 60 & 40 & 65 & 35 & 73 & 27 \\
\hline Airway assessment - anatomical issues/observations & 40 & 60 & 12 & 88 & - & - \\
\hline Airway assessment - mallampatti score & 29 & 71 & - & - & - & - \\
\hline Airway assessment - mandibular thyroid distance & 29 & 71 & - & - & - & - \\
\hline Does patient have a history/family history of malignant hyperthermia? & 63 & 37 & 56 & 44 & 76 & 24 \\
\hline Dentition & 100 & 0 & - & - & - & - \\
\hline Vital signs attended & 91 & 9 & - & - & - & - \\
\hline Is pre-operative warming required? & 51 & 49 & 26 & 74 & - & - \\
\hline Foetal heart rate? & 49 & 51 & 27 & 73 & - & - \\
\hline Height and weight & 80 & 20 & - & - & - & - \\
\hline BMI & 54 & 46 & 41 & 59 & 24 & 76 \\
\hline Is a HoverMatt required? & 51 & 49 & 38 & 62 & 36 & 64 \\
\hline ECG attended & 80 & 20 & - & - & - & - \\
\hline Date and time of last oral intake - solids & 97 & 3 & - & - & - & - \\
\hline $\begin{array}{l}\text { Confirm list of all current medications including prescription, over the } \\
\text { counter, etc. }\end{array}$ & 74 & 26 & - & - & - & - \\
\hline
\end{tabular}

Table 1.4: Assessment items

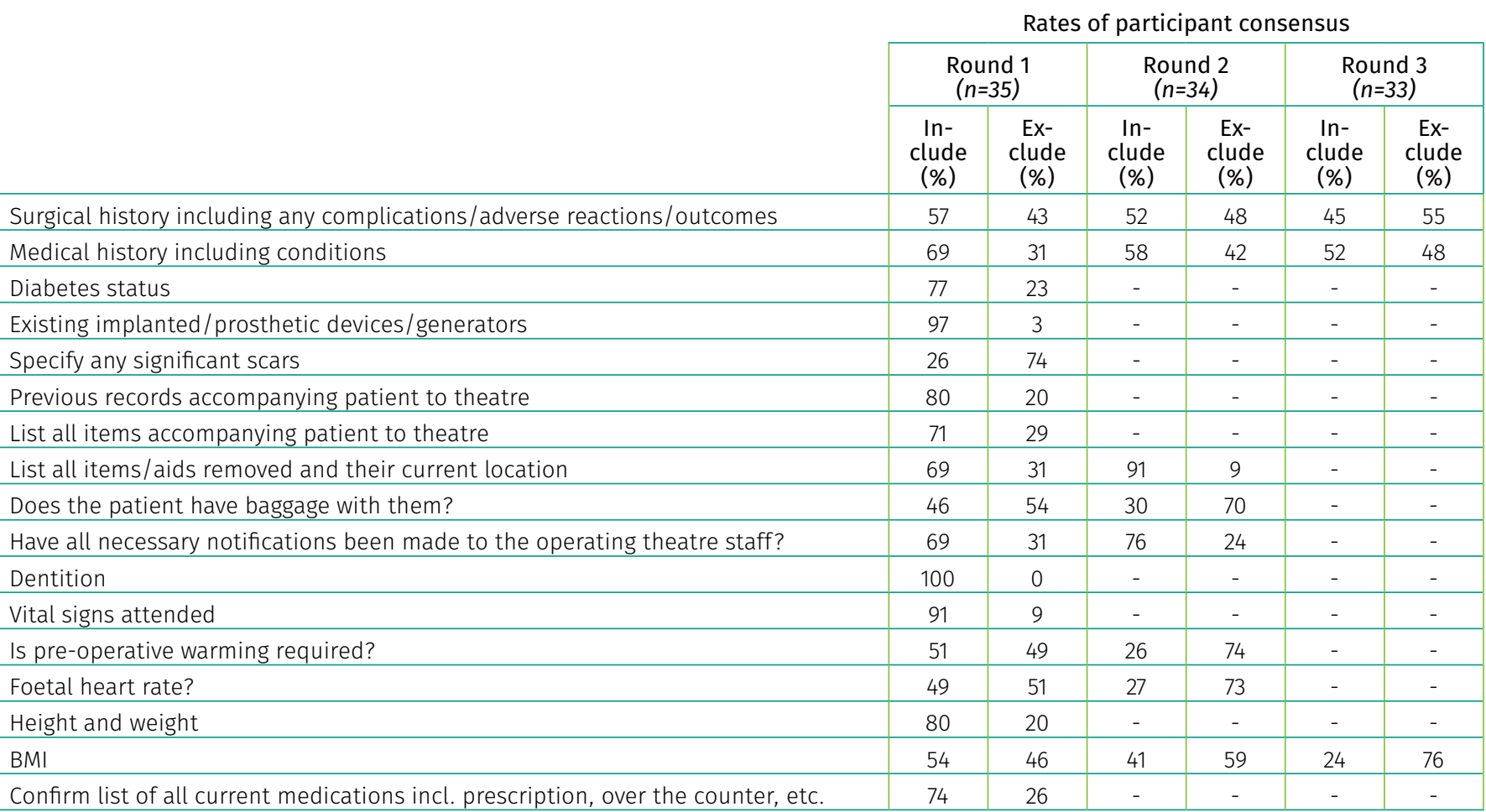

Confirm list of all current medications incl. prescription, over the counter, etc.

Table 1.5: Assessment items

Data analysis: Survey responses were analysed for consensus which, in this study, was considered to be agreement between at least 70\% of participants 14,7 . Once consensus was reached either for inclusion or exclusion, each item was removed from future surveys. The process was then repeated until three survey rounds were complete.

Ethics: Ethics approval was obtained from the University of Tasmania Social Sciences Human Research Ethics Committee (Ethics ref: H0014042). 


\begin{tabular}{|c|c|}
\hline Characteristics & $n(\%)$ \\
\hline \multicolumn{2}{|l|}{ Gender } \\
\hline Female & $35(100)$ \\
\hline \multicolumn{2}{|l|}{ Age (years) } \\
\hline$<30-39$ & $10(29)$ \\
\hline $40->60$ & $25(71)$ \\
\hline \multicolumn{2}{|l|}{ Designation } \\
\hline EN/RN & $7(20)$ \\
\hline $\mathrm{CNS} / \mathrm{NE} / \mathrm{CNE} / \mathrm{CNC} / \mathrm{NP}$ & $18(51)$ \\
\hline A/NUM/Manager/Director & $10(29)$ \\
\hline \multicolumn{2}{|l|}{ Specialty } \\
\hline Anaesthetics/Recovery & $10(29)$ \\
\hline Instrument/Circulating & $11(31)$ \\
\hline A combination of areas & $14(40)$ \\
\hline
\end{tabular}

\begin{tabular}{|c|l|}
\hline \multicolumn{2}{|c|}{ Duration of nursing service (years) } \\
\hline Did not state & $2(6)$ \\
\hline $5-14$ & $8(23)$ \\
\hline $15->20$ & $25(71)$ \\
\hline
\end{tabular}

Duration of perioperative nurse service (years)

\begin{tabular}{|c|l|}
\hline 5-14 & $12(34)$ \\
\hline \multicolumn{1}{|l|}{$15->20$} & $23(66)$ \\
\hline \multicolumn{2}{|l|}{ Employment status } \\
\hline Agency/Contract & $2(6)$ \\
\hline Permanent full-time & $26(74)$ \\
\hline Permanent part-time & $7(20)$ \\
\hline \multicolumn{2}{|l|}{ Type of facility } \\
\hline Private hospital & $14(40)$ \\
\hline
\end{tabular}

\begin{tabular}{l|l} 
Public hospital & $20(57)$ \\
\hline
\end{tabular} $\begin{array}{ll}\text { Private and public hospitals } & 1(3)\end{array}$

Primary perioperative nursing role

\begin{tabular}{|l|l|}
\hline Did not state & $1(3)$ \\
\hline Direct patient care & $14(40)$ \\
\hline Education & $9(26)$ \\
\hline Management and clinical & $9(26)$ \\
\hline Consultant & $2(6)$ \\
\hline
\end{tabular}

Highest nursing qualification

Bachelor degree

Certificate (hospital trained) 3 (9)

Diploma/Advanced Diploma 2 (6)

Grad Cert/Dip/Masters $22(62)$

Table 2: Characteristics of participants

Demographic

Participant demographic data is expressed in Table 2. All participants were female ( $n=35)$. Forty-nine per cent $(n=17)$ of participants had more than 20 years' experience in perioperative nursing. The majority of participants $(n=26,74 \%)$ were employed on a full-time basis. Sixty-eight per cent $(n=24)$ of participants were graduate certificate, diploma or masters degree qualified.

\section{Results}

\begin{tabular}{|c|c|}
\hline \multirow{6}{*}{$\begin{array}{l}\text { Patient and Procedure } \\
\text { Verification }\end{array}$} & Patient communication issues identified \\
\hline & Patient and staff verify procedure (including site and side) \\
\hline & Patient and staff verify identification (name and date of birth) \\
\hline & Consent for procedure and blood products verified \\
\hline & Patient ID and alert bands verified and applied \\
\hline & Handover of care documented \\
\hline \multirow{8}{*}{ Preparation } & Staff and patient concerns documented and communicated to team \\
\hline & Pre-medication/medications verified \\
\hline & High-risk medications identified (e.g. cytotoxic, anticoagulants) \\
\hline & Surgical site prepared (e.g. marked, pre-op shower, clipped, bowel prep) \\
\hline & VTE prophylaxis verified \\
\hline & Accessories and aids removed/secured \\
\hline & Fluid, fasting and hydration status documented \\
\hline & Existing implanted/prosthetic devices documented \\
\hline \multirow{11}{*}{ Assessments } & Infection status and precautions verified \\
\hline & Appropriate pathology attended (e.g. group and hold/screen, INR, glucose) \\
\hline & Medical imaging and other accompanying items verified \\
\hline & Pressure injury risk and skin integrity documented \\
\hline & Mobilisation and manual handling requirements documented \\
\hline & Malignant hyperthermia history documented \\
\hline & Dentition documented \\
\hline & Baseline vital signs attended \\
\hline & Height and weight documented \\
\hline & ECG attended \\
\hline & Diabetes status documented \\
\hline
\end{tabular}

Table 3: Pre-operative checklist 
A total of 36 nurses consented to participate in this study. All volunteers were included in the study. Questionnaire one had a $97 \%$ response rate $(n=35 / 36)$. The second and third questionnaires were only sent to those participants who completed the first questionnaire. Questionnaire two had a $97 \%$ response rate $(n=34 / 35)$. Questionnaire three was completed by $94 \%$ of participants $(n=33 / 35)$.

The participants determined that 46 of the 77 items should be included in a pre-operative checklist. Following data analysis, these 46 items were condensed to a list of 25 checklist items, presented in Table 2. These items were categorised as: 1. Patient/ procedure verification; 2. Preparation; and 3. Assessment.

\section{Discussion}

The final list of 25 checklist items is intended for use as a guide when developing a pre-operative checklist. Some items may not be relevant to all facilities, procedures or patients and should be omitted or altered as appropriate. It is important to reduce repetition in pre-operative checklists and individualise patient assessment ${ }^{13}$.

Patient and procedure verification items relate to health service policy directives, Australian College of Operating Room Nurses (ACORN) Standards ${ }^{10}$ and Australian National Standards ${ }^{18}$. The importance of patient identification and informed consent is also highlighted by Zastrow $^{13}$. Incorrect patient and procedure identification can lead to wrong patient or procedure and medication, diagnostic testing and transfusion errors, all of which have the potential for dire consequences ${ }^{19}$.

Zastrow $^{13}$ states that the preoperative phase of the perioperative journey involves assessment of the patient's sensory impairments or language barriers as well as noting any friends, family or significant others present during assessment. Participants in this study agreed that any foreseeable communication issues should be noted on the preoperative checklist but specifying whether an interpreter was required did not achieve consensus after three survey rounds. A number of participants stated that this item had no place on the pre-operative checklist as it was 'too late' and should be arranged earlier. Other participants disagreed, many stating 'never too late to ensure patient safety'. Participants were also presented with a checklist item to specify anyone present at handover to the operating theatre environment but consensus was not achieved on this item either. Many participants felt this information was 'not relevant' to a pre-operative checklist.

Items categorised as Preparation ensure that the patient and all members of the multidisciplinary team are adequately prepared for the intended procedure. Items in this category are supported by Zastrow ${ }^{13}$ and are represented within ACORN Competency Standards ${ }^{10}$.

Participants suggesting inclusion of pre-medication and regular medication checklist items were concerned about the effect of premedications on patients' capacity to consent. Participants wanting to include this item were also concerned about patient safety, which may be compromised by administration of pre-medication if the patient was not adequately monitored. Comments included 'are they able to sign/complete the consent legally?', 'Do they need to be on oxygen and be monitored? Are they having a reaction, what to?' Participants chose to include an item which identified high-risk medications such as cytotoxic agents. Comments in support of this item included 'need to use cytotoxic-specific/appropriate personal protective equipment'. Comments supporting exclusion of this item included 'not sure how this would affect the theatre process ... anaesthetist should be aware'. ACORN Competency Standards ${ }^{10}$ state that the perioperative nurse is responsible for identifying biohazards such as cytotoxic drugs.

All items categorised under Assessment are identified in ACORN Competency Standards ${ }^{10}$ as the responsibility of the perioperative nurse to address. Assessment items include identification of known infection status, ensuring necessary pathology has been attended, documenting any medical imaging or other items accompanying the patient to theatre, completion of risk assessments, dentition and gathering baseline data such as vital signs, height and weight and ECG.

Participants suggesting infection status be excluded commented 'should be identified well before the operating room,' 'patients don't often know correct details ... this would just lead to confusion'. Participants who selected include commented that this identifies the need for specific infection control measures.

Pathology may include INR and 'group and hold/screen'. Participants choosing to include these items commented '[if results not available]... we chase up ... may be essential to surgery and progression' and 'as applicable', ' [include for] major cases only'. Participants suggesting these items be excluded commented that this should have been addressed prior to completion of pre-operative checklist and 'anaesthetics deal with this'.

ACORN Competency Standards ${ }^{10}$ state that the perioperative nurse should conduct an anaestheticrelated assessment of past history including previous problems with surgery and anaesthesia and assessment and action as required regarding potential for perioperative hypothermia. Zastrow ${ }^{13}$ also identifies anaesthetic and surgical history as 
a responsibility of the perioperative nurse. Hamlin, Richardson-Tench and Davies ${ }^{11}$ highlight the importance of perioperative hypothermia risk assessment and pre-warming as required as a perioperative nursing responsibility. Each of these items were presented to participants; however, anaesthesia and surgical history and problems did not achieve consensus for inclusion or exclusion and a separate item relating to perioperative hypothermia was excluded by participants. Participants wanting to include pre-operative warming needs on the checklist believed this item would minimise intra- and post-operative hypothermia and stated that prewarming would have a positive impact on pain management and recovery time. Other participants who voted to exclude pre-operative warming from the checklist stated that this is the responsibility of the anaesthetist and 'all patients can benefit from pre-operative warming'. This suggests that they felt prewarming was important but that it did not belong on the pre-operative checklist. Participants suggested including anaesthetic and surgical history-taking as this presents an opportunity to identify potential problems. Other participants suggested excluding these items as they believed collection of this information should be conducted on admission to hospital and also that the anaesthetist is responsible for collection of this information, not the nurse.

Many participants selected exclude for multiple checklist items, commenting 'anaesthetics deal with this'. Participants had experience in anaesthetics, post-anaesthetic care, instrument and circulating nursing. Opinions and comments emerging from this study suggest nurses require greater understanding of the roles and priorities of nurses in perioperative specialities which differ from their own.
It is recommended that education be provided for perioperative nurses to better understand the roles of other nursing specialities within the perioperative environment. Thorough understanding of the roles and priorities of other nurses will allow nurses admitting patients to the perioperative environment to promote patient safety and effective communication throughout the perioperative journey. Education should also be provided on the content of the pre-operative checklist and the implications of each item on patient safety.

\section{Strengths and limitations}

The strength of these findings is the use of expert opinion and the achievement of a high response and participant retention rate. The e-Delphi method is cost-effective and provides access to expert opinion without geographical limitations or the time restrictions placed on face-to-face data collection. Ensuring participants remained anonymous to each other allowed panellists to change their position on a matter based on group feedback, without the need to defend such change, avoiding the undue influence of experts and ensuring no member dominated the expert panel${ }^{20}$. Across the three survey rounds, upon sharing panellists' feedback, many participants' positions shifted. These shifts in opinion show that the sharing of anonymous feedback allows participants to interact and change their position across survey rounds. This is further evident in participant comments such as: 'Agree with above notes' and 'I agree with all of the above comments - these provide a valid rationale'.

Recruitment via ACORN may initially appear to have been a limitation; however, participants were not required to be members of the College. A number of participants were recruited by ACORN members who had shared the study poster and information sheet with colleagues.

This work contributes to the limited body of literature informing the content of pre-operative checklists. All items in the final checklist are supported by current ACORN Competency Standards ${ }^{10}$, Australian Commission for Safety and Quality in Health Care National Health Standards ${ }^{19}$ and current literature ${ }^{11-13}$

\section{Conclusion}

Patients are vulnerable when in perioperative environments. Surgical safety initiatives exist for use during the intraoperative phase to encourage communication and teamwork. The pre-operative period provides the final opportunity to verify and gather new information prior to anaesthetic and surgical interventions; however, very little research has been conducted in this area.

The findings of this study provide an evidence base for development of pre-operative checklists to promote patient safety and effective communication in the perioperative environment. Checklist items are categorised as: 1. Patient and procedure verification; 2. Preparation; and 3. Assessments. Further research and education is required to effectively use pre-operative checklists as a tool to improve patient safety and communication in the perioperative environment.

\section{References}

1. Reason J (1995). Safety in the operating theatre - Part 2: human error and organisational failure. Current Anaesthesia Vol. 6, pp. 121-126.

2. World Health Organization (2014). 10 facts on patient safety. www.who.int/features factfiles/patient_safety/en/ Accessed 14 March, 2014

3. Alnaib $M, A$ A Samaraee $A$ \& Bhattacharya $V$ (2012). The WHO Surgical Safety Checklist. Journal of Perioperative Practice Vol. 22, No. 9, pp. 289-292. 
4. Birkmeyer JD (2010). Strategies for improving surgical quality - checklists and beyond. The New England Journal of Medicine, Vol. 363, No. 20, pp. 1963-1965.

5. O'Connor P, Reddin C, O'Sullivan M, O'Duffy F \& Keogh I (2013). Surgical checklists: the human factor. Patient Saf Surg Vol. 7, No. 1, p. 14.

6. World Alliance for Patient Safety (2009). Implementation Manual Surgical Safety Checklist. First ed: World Health Organisation. whalibdoc.who.int/ publications/2009/9789241598590_eng.pdf Accessed $8^{\text {th }}$ November 2013.

7. Bell R \& Pontin L (2010). How implementing the surgical safety checklist improved staff teamwork in theatre. Nursing Times, Vol. 106, No. 12.

8. Jones S (2011). Your life in WHO's hands: the World Health Organisation surgical safety checklist. Journal of Perioperative Practice, Vol. 21, No. 8, pp. 271-274.

9. Fudickar A, Horle K, Wiltfang J \& Bein B (2012). The effect of the WHO Surgical Safety Checklist on complication rate and communication. Dtsch Arztebl Int, Vol. 109, No. 42, pp. 695-701.

10. The Australian College of Operating Room Nurses Ltd (ACORN).(2014). ACORN Standards for Perioperative Nursing. Adelaide, South Australia: ACORN.

11. Hamlin L, Richardson-Tench M \& Davies $M$ (2009). Perioperative nursing: an introductory text. Sydney: Elsevier Australia

12. Sweitzer B (2008). Preoperative assessment and management. 2nd edn. Philadelphia, PA: Wolters Kluwer.

13. Zastrow S (2009). Perioperative nursing assessments made simple. OR Nurse, Vol. 3 , No. 4, pp. 16-17.

14. Keeney S, Hasson F \& McKenna H (2011). The Delphi Technique in Nursing and Health Research. West Sussex: Wiley-Blackwell.

15. Gill F, Leslie G, Grech C \& Latour J (2013). Using a web-based survey tool to undertake a Delphi study: application for nurse education research. Nurse Education Today, Vol. 33, No. 11, pp. 1322-1328.

16. SurveyMonkey (2014). SurveyMonkey. Accessed 28 March, 2014
17. Vernon W (2009). The Delphi Technique: A Review. International Journal of Therapy and Rehabilitation Vol. 16, No. 2, pp. 69-76.

18. Australian Commission on Safety and Quality in Health Care (ACSQHC) (2014). Patient identification. National Standards and Accreditation www.safetyandquality. gov.au/our-work/patient-identification/ Accessed 29 ${ }^{\text {th }}$ August 2014.

19. Australian Commission for Safety and Quality in Health Care (ACSQHC) (2012). Specifications for a standard patient identification band. www.safetyandquality. gov.au/wp-content/uploads/2012/02/ FactSheet-PatID-Band.pdf Accessed $4^{\text {th }}$ September 2014.

20. de Meyrick J (2003). The Delphi method and health research. Health Education, Vol. 103, No. 1, pp. 7-16.

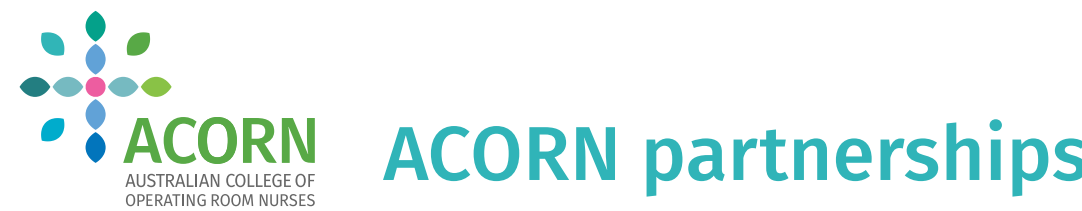

ACORN invites all interested providers of education for perioperative nurses, to accredit courses with us. Currently there are fifteen ACORN accredited courses available. Information can be found at www. acorn. org. au/education/course-accreditation/

ACORN believes that collaborating with the education sector will improve course quality and appropriateness, and therefore assist hospitals and nursing staff to provide an improved standard of care.

ACORN wishes to clarify some questions that have been raised regarding ACORN's relationship with the University of Tasmania (UTAS).

1. UTAS are offering HECS fee waivers to ACORN members in return for our input into their curriculum. ACORN believes that this is a big step forward in ensuring that courses provide content suitable to the perioperative workplace.

2. ACORN is not funding the scholarships offered.

3. ACORN is not receiving financial benefit.

4. The ACORN and UTAS partnership is not exclusive. ACORN has welcomed all providers of perioperative education to seek accreditation with ACORN for a number of years. Details are on our website.

5. ACORN entered into a Memorandum of Understanding with UTAS to provide benefit to our members. Three hundred members have taken up the opportunity for further study since June 2015. In addition, many have applied to undertake casual marking or tutoring, an opportunity that may not otherwise have been available. 